\title{
Polybenzoxazine Resins with Cellulose Phosphide: Preparation, Flame Retardancy and Mechanisms
}

\author{
Hui Li ${ }^{1, *}$, Zhangmei Sun ${ }^{1}$, Chunxia Zhao ${ }^{1, *} \mathbb{D}$, Yuntao $\mathrm{Li}^{1,2}$, Dong Xiang ${ }^{1}$, Yuanpeng Wu ${ }^{1,3}$, Jixuan Wei ${ }^{1}$ \\ and Yusheng Que ${ }^{1}$ \\ 1 School of New Energy and Materials, Southwest Petroleum University, Chengdu 610500, Sichuan, China; \\ Aa2515954054@163.com (Z.S.); yuntaoli@swpu.edu.cn (Y.L.); d.xiang@swpu.edu.cn (D.X.); \\ wuyp362@126.com (Y.W.); wjx15076120896@163.com (J.W.); m15351372549@163.com (Y.Q.) \\ 2 State Key Laboratory Oil and Gas Reservoir Geology and Exploitation, School of New Energy and Materials, \\ Southwest Petroleum University, Chengdu 610500, Sichuan, China \\ 3 The Center of Functional Materials for Working Fluids of Oil and Gas Field, School of New Energy and \\ Materials, Southwest Petroleum University, Chengdu 610500, Sichuan, China \\ * Correspondence: lihui@swpu.edu.cn (H.L.); polychem@swpu.edu.cn (C.Z.)
}

Citation: Li, H.; Sun, Z.; Zhao, C.; Li, Y.; Xiang, D.; Wu, Y.; Wei, J.; Que, Y. Polybenzoxazine Resins with Cellulose Phosphide: Preparation, Flame Retardancy and Mechanisms. Polymers 2021, 13, 4288. https:// doi.org/10.3390/polym13244288

Academic Editors: Zhi Li, Jun Sun and Yangquan Shi

Received: 8 November 2021

Accepted: 2 December 2021

Published: 7 December 2021

Publisher's Note: MDPI stays neutral with regard to jurisdictional claims in published maps and institutional affiliations.

Copyright: (c) 2021 by the authors. Licensee MDPI, Basel, Switzerland. This article is an open access article distributed under the terms and conditions of the Creative Commons Attribution (CC BY) license (https:// creativecommons.org/licenses/by/ $4.0 /)$.
Abstract: Phosphated cellulose (PCF) was synthesized based on urea, phosphated acid and cellulose. The structure of the PCF was confirmed by Fourier transform infrared (FTIR) spectroscopy and scanning electron microscopy coupled with the Energy Dispersive Spectrometer (SEM-EDS). Benzoxazine (Ba)/PCF hybrid materials were fabricated and thermally cured to prepare polybenzoxazine composites (PBa/PCF). The effects of PCF on the curing temperature of Ba were analyzed through differential scanning calorimetry (DSC). The thermogravimetric (TGA) results demonstrated an increased char residue of $50 \%$ for the PBa composites incorporating PCF- $5 \%$ compared with the pure PBa. The peak heat release rate (PHRR) and total heat release (THR) values of the PBa/PCF-5\% composites clearly decreased by $58.1 \%$ and $16.5 \%$ compared to those of the pristine PBa. The smoke released from the $\mathrm{PBa} / \mathrm{PCF}$ system significantly reduced with the loading of PCF. Moreover, the limited oxygen index (LOI) and vertical burning test level (UL-94) of PBa/PCF-5\% reached up to 31 and V0. The flame retardant mechanism of the PCF in the PBa matrix was investigated TG-FTIR and char residues analysis. Finally, the dynamical mechanical analysis (DMA) results demonstrated that the $\mathrm{Tg}$ of the $\mathrm{PBa} / \mathrm{PCF}$ composites was approximately $230^{\circ} \mathrm{C}$, which does not affect further applications of $\mathrm{PBa}$ composites.

Keywords: thermosets; flame retardant; phosphate cellulose; thermal properties

\section{Introduction}

Polybenzoxazine (PBa) is a new type phenolic resin, which can be synthesized by formaldehyde, primary amines and phenols through Mannch reaction [1-3]. PBa offers outstanding performance in comparison to traditional phenolic resin, such as its flexible molecular design, near-zero shrinkage behavior during polymerization, low water absorption, low dielectric constant, low coefficient of thermal expansion and so on [4-8]. These characteristics make it possible to broaden the application prospects of PBa beyond aerospace, electronics and automobile manufacturing [9-13]. However, PBas, especially those that are bisphenol-A-based, are easy to flame with a limited oxygen index (LOI) of about 21, which makes them undesirable for many engineering applications. Various kinds of flame retardants and fire-quenching strategies have been developed to reduce the high combustibility of PBa. The intrinsic chemical flame retarding method involves introducing flame retardancy elements into the PBa molecular chain based on the flexible molecular design of benzoxazine (Ba) monomers. Zhu et al. synthesized novel Ba monomers from P-nitrophenol, paraformaldehyde and aniline [14]. The nitro group promoted the ring-opening polymerization of Ba monomers, as well as favoring higher thermal stability and char residue of $\mathrm{PBa}$ compared to the phenol-aniline-based $\mathrm{Ba}$ monomers and 
polymers, respectively. Lin et al. synthesized a novel flame retardant PBa copolymer with phosphorus-containing Ba monomers [15]. The glass transition temperature $\left(\mathrm{T}_{\mathrm{g}}\right)$, thermal decomposition temperature $\left(\mathrm{T}_{\mathrm{d}}\right)$ and flame retardancy of the PBa were all clearly enhanced. Halogen-free flame-retardant additives have recently attracted much attention from both researchers and industrialists due to their environment-friendly, convenience, low cost and high efficiency $[16,17]$. Demir et al. prepared a new class of polybenzoxazine/montmorillonite (PBa/MMT) nanocomposites and the char yield increased from $16 \%$ to $35 \%$ with $10 \%$ of MMT [18]. PBa composites based on $\alpha$-zirconium phosphate $(\alpha-\mathrm{ZrP})$ demonstrated improved thermal stability and char residue formation [19]. Amongst all halogen-free flame-retardant additives, phosphorous-containing compounds are popular non-halogen additives, known to be effective at improving the flame retardancy of polymers through their ability to promote char layer formation. The PBa composite exhibited a $62.5 \%$ reduction in peak values of heat release (PHRR)and a $49.3 \%$ decrease in total heat release (THR) with the incorporation of $5 \%$ polyphosphazene microspheres [20]. Meanwhile, epoxy resin (EP) cured by a phosphorus-containing hardener mixture exhibited significantly reduced THR and total smoke production [21]. In Hong et al.'s work [22], a novel piperazine-containing additive with phosphorus and alkyny (PPBPP) was used to flame-retard thermo-plastics polyurethane (TPU). They found that $3.0 \mathrm{wt} \%$ PPBPP endowed TPU with a UL-94 V-0 rating. Phosphorus-based flame retardants can produce phosphoric acid, polyphosphoric acid during heating. These acid products promote the dehydration and carbonization of substrate to form the char layer, which prevents the transfer of oxygen, heat and mass between the burning zone and the inner, unburnt area [23-25]. In addition, phosphorus-containing radicals produced by the decomposition of phosphorous flame retardant can capture radicals in the gas phase and terminate chain reaction, as well as reducing the further decomposition of polymer materials [26,27]. With the current focus on the sustainable development of society, renewable bio-based flame retardant agents have gained extensive attention. Currently, bio-based materials, such as amino trimethylene phosphonic acid (ATMP), starch, lignin, $\beta$-cyclodextrin and chitosan (CS) are used as eco-friendly additives to improve the flame retardancy of polymers [28-31]. Thirukumaran et al. prepared a new class of modified chitosan-based benzoxazine precursor/amino cellulose ((E-ch/AC) film [32]. The mechanical performance, thermal properties and char yield of the polymer films all improved.

Inspired by the above published reports, phosphated cellulose (PCF) was synthesized and used to improve the flame retardancy of PBa in this work. The effects of PCF on the thermal stability, flame retardancy, burning behavior and mechanical properties of PBa were measured and discussed. The flame retardant mechanism of the composite was investigated by analyzing char residues and gas phase products.

\section{Experimental Section}

\subsection{Materials}

Bisphenol A-based benzoxazine (Ba) was provided by Sichuan Tiance Jucai Technology Co., Ltd. (Chengdu, China). The 98\% phosphite, $99.5 \%$ urea, ethanol, and acetone were purchased from Chengdu Kelong Chemical Reagent Factory (Chengdu, China). The $50 \mu \mathrm{m}$ cellulose was supplied by Innochem (Beijing, China). All the chemicals were used as received without further purification.

\subsection{Phosphorylation of $\alpha$-Cellulose}

Phosphated cellulose (PCF) was synthesized according to previous research [33]. To begin with, $12.48 \mathrm{~g}(0.208 \mathrm{~mol})$ urea was added into a $250 \mathrm{~mL}$ three-neck bottle and heated to $140{ }^{\circ} \mathrm{C}$ in a $\mathrm{N}_{2}$ atmosphere until the urea was dissolved completely. Next, $2.00 \mathrm{~g}(0.0123 \mathrm{~mol})$ cellulose and $10.28 \mathrm{~g}(0.1253 \mathrm{~mol})$ phosphorous acid were added alternately to the molten urea. The reaction was carried out at $150{ }^{\circ} \mathrm{C}$ for $6 \mathrm{~h}$. The reacted mixture was dissolved in $250 \mathrm{~mL} 1 \mathrm{~N}$ aqueous sodium hydroxide and precipitated with ethanol. This process was repeated three times, in order to remove the urea and the un- 
reacted phosphite. The modified cellulose was freeze dried. The final phosphorylated cellulose was light yellow and water-soluble. The phosphating process of the cellulose is shown in Figure 1.

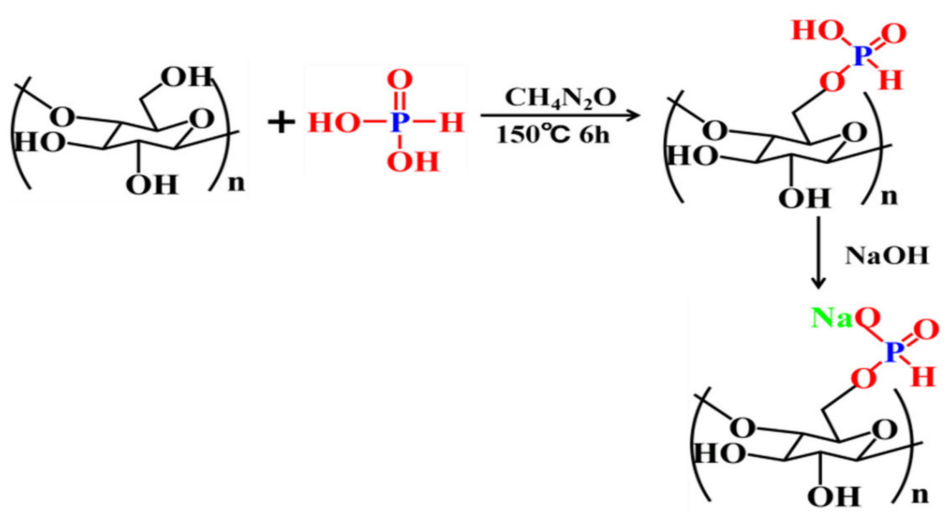

Figure 1. The phosphating process of cellulose.

\subsection{Preparation of $\mathrm{PBa} / \mathrm{PCF}$ Composites}

First of all, $0.9 \mathrm{~g}$ PCF and $90 \mathrm{~g}$ Ba were distributed in $30 \mathrm{~mL}$ acetone in a $250 \mathrm{~mL}$ three-necked flask under ultrasound at room temperature. Next, the acetone was removed by oil-bath heating, aided by a rotary evaporator. Finally, the mixture was poured into a glass, mold treated with release agent and preheated for curing at $180^{\circ} \mathrm{C} / 2 \mathrm{~h}$, followed by $200{ }^{\circ} \mathrm{C} / 2 \mathrm{~h}$. The cured product was labeled as PBa/PCF- $1 \%$. The pure PBa, $\mathrm{PBa} / \mathrm{PCF}-3 \%$ and $\mathrm{PBa} / \mathrm{PCF}-5 \%$ were produced in a similar process. The chemical structure and curing reaction of Ba are shown in Figure 2.

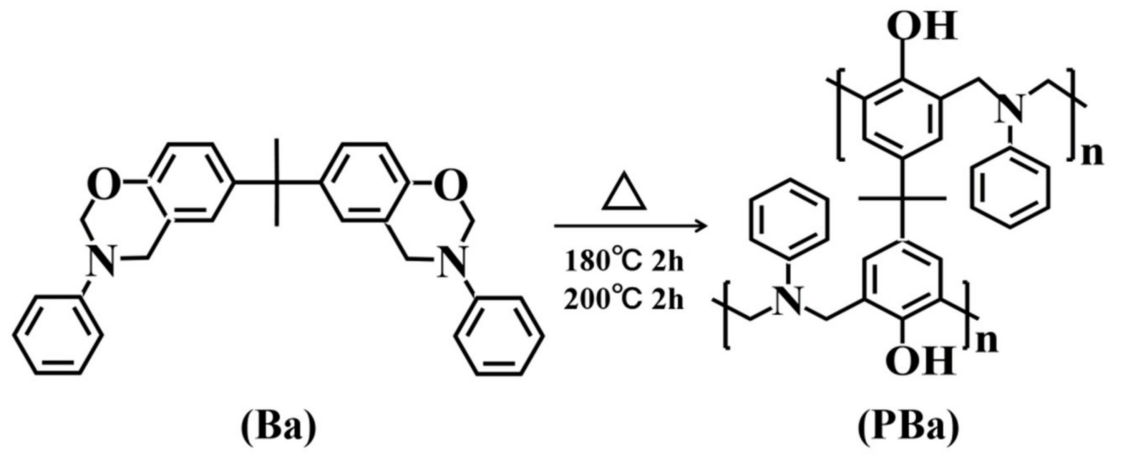

Figure 2. The chemical structure and curing reaction of Ba.

\subsection{Characterization}

The surface functional group of pulverized phosphatized cellulose powder was tested through Fourier transform infrared (FTIR) spectroscopy using a Nicolet 6700 spectrometer (Thermo Electric Corporation, West Chester, PA, USA) in the range of $4000-500 \mathrm{~cm}^{-1}$. The morphology of the samples was analyzed through the scanning electron microscope (SEM) platform, using a ZEISS EV0 MA15 SEM from Carl Zeiss Micro Image Co., Ltd. (Jena, Germany) The elemental analysis of the sample was implemented in EDS using a ZEISS EV0 MA15 from Carl Zeiss Micro Image Co., Ltd. The thermal stabilities were measured on a thermogravimetric analyzer (DSC823 TGA/SDTA85 ${ }^{\mathrm{e}}$ ) in a nitrogen and air atmosphere with a heating rate of $10^{\circ} \mathrm{C} / \mathrm{min}$, from $40^{\circ} \mathrm{C}$ to $80{ }^{\circ} \mathrm{C}$. The curing temperature of the $\mathrm{Ba}$ and $\mathrm{Ba} / \mathrm{PCF}$ mixtures was measured using non-isothermal DSC Q20 (TA Instruments, New Castle, DE, USA) at a heating rate of $10^{\circ} \mathrm{C} / \mathrm{min}$ from $40^{\circ} \mathrm{C}$ to $300^{\circ} \mathrm{C}$. The fire performance of the materials was analyzed using a Cone calorimetry (CONE) test by ASTME1354/ISO 5660. The size of the samples was $100 \times 100 \times 3.2 \mathrm{~mm}^{3}$. The samples were enclosed in aluminum foil and measured at $35 \mathrm{~kW} / \mathrm{m}^{2}$ heat flow conditions. A dynamic mechanical analysis (DMA) was carried out using a Q800 analyzer (TA Instruments) 
from 40 to $300{ }^{\circ} \mathrm{C}$, at a heating rate of $5{ }^{\circ} \mathrm{C} /$ step, with a frequency of $1 \mathrm{~Hz}$ in air. Samples with dimensions of $40 \times 10 \times 3.2 \mathrm{~mm}^{3}$ were used. A thermogravimetric-Fourier transform infrared (TG-FTIR) analysis was performed using a Perkin-Elmer STA 6000 (Waltham, MA, USA) in a nitrogen and air atmosphere, with a heating rate of $10^{\circ} \mathrm{C} / \mathrm{min}$ from $40^{\circ} \mathrm{C}$ to $800^{\circ} \mathrm{C}$. The limiting oxygen index (LOI) values were tested using an HC-2C Oxygen Index Flammability Gauge (Jiangning, China), according to ASTM D2863-97. The dimensions of all the samples were $130 \times 3.5 \times 3.2 \mathrm{~mm}^{3}$. The vertical burning test (UL-94) was carried out on a CZF-2 instrument (Jiangning, China), according to GT/T 8333-2008. The dimensions of all the samples were $125 \times 12.7 \times 3.2 \mathrm{~mm}^{3}$. The structures of the char residues obtained from the CONE test were obtained through Raman spectroscopy, using a ID Raman micro IM-52 from Ocean Optics (Dunedin, FL, USA) fitted with a laser, at a wavelength of $785 \mathrm{~nm}$.

\section{Results and Discussion}

\subsection{Characterization of PCF}

The cellulose took the form of a white-like powder and was not insoluble in water, as shown in Figure 3(a1,a2), respectively. Clearly, the PCF changed to faint yellow and dissolved in water to form a transparent solution (Figure 3(b1,3b2)), which preliminarily demonstrated the phosphating reaction of the cellulose. Cellulose macromolecule belongs to polysaccharide, which is composed of D-glucose with $\beta-1,4$ glycosidic bonds [34]. The abundant hydroxyl groups in cellulose make it easy to be modified. It has been reported that phosphoric acid could react with the hydroxyl group on the C-6 atom in cellulose [35-38]. The FTIR spectra of cellulose and PCF are presented in Figure 3(c1,c2). The characteristic absorption peaks of cellulose at $1160 \mathrm{~cm}^{-1}$ and $1120 \mathrm{~cm}^{-1}$ belong to the vibration of the $-\mathrm{C}-\mathrm{O}-\mathrm{C}$ - in the glucoside unit or $\beta-(1-4)$ glucosinic bonds. The peaks from $2850-3000 \mathrm{~cm}^{-1}$ were attributed to the $-\mathrm{C}-\mathrm{H}$ stretching vibration of the $-\mathrm{CH}_{2}$ groups. The characteristic absorption peak of $3469 \mathrm{~cm}^{-1}$ corresponds to the vibration for the $-\mathrm{OH}$ groups. The intensity of the $-\mathrm{OH}$ stretching of PCF clearly weakened, proving that the $-\mathrm{OH}$ group on the $\mathrm{C}-6$ atom in $\alpha$-Cellulose was consumed during the phosphating reaction. New peaks appeared at the PCF FTIR spectrum (Figure 3(c2)): the characteristic absorption peak at $2393 \mathrm{~cm}^{-1}$ corresponded to the $\mathrm{P}-\mathrm{H}$ absorption, the peak at $889 \mathrm{~cm}^{-1}$ was due to the $\mathrm{P}-\mathrm{O}-\mathrm{C}$ absorption and the peaks at $1269 \mathrm{~cm}^{-1}$ were attributed to the $-\mathrm{P}-\mathrm{O}-$ absorption. Furthermore, the characteristic peak at $1134 \mathrm{~cm}^{-1}$ was ascribed to the absorption of $-\mathrm{P}=\mathrm{O}$ in PCF. The above phenomena and discussion confirm the successful phosphating reaction of the cellulose.

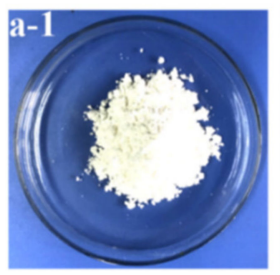

a-2

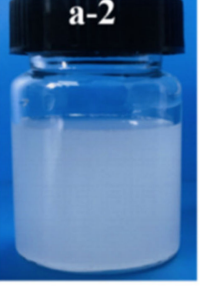

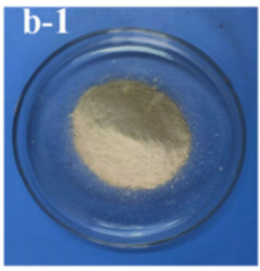

b-2

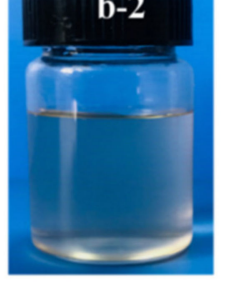

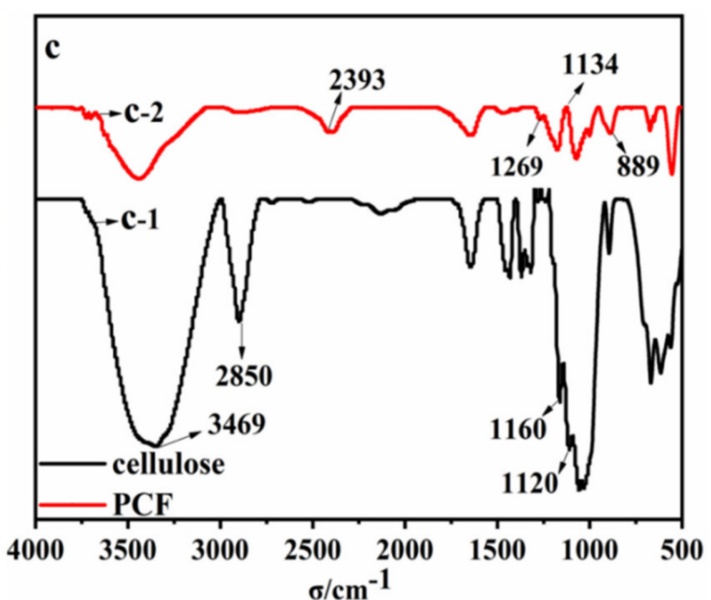

Figure 3. Comparison of the morphology and solubility in water of cellulose $(\mathbf{a}-\mathbf{1}, \mathbf{a}-\mathbf{2})$ and PCF $(\mathbf{b}-\mathbf{1}, \mathbf{b}-\mathbf{2})$; FITR of cellulose (c-1) and PCF (c-2). 


\subsection{Morphology of Cellulose and PCF}

The morphologies of the cellulose (Figure 4a) and PCF (Figure $4 \mathrm{~b}$ ) were investigated by SEM. Apparently, cellulose without phosphorylation is in a discrete state and features a smooth surface. However, PCF exhibits clear fibrous tissue with a rough surface, which can be obtained by freeze drying. An EDS test was performed to detect the presence of P element with a PCF content of about $9.5 \%$. The uniform distribution of the P elements can be seen in Figure $4 \mathrm{~d}$, marked as blue signals. The analysis of FTIR and SEM-EDS proved the successful preparation of the PCF in this study.
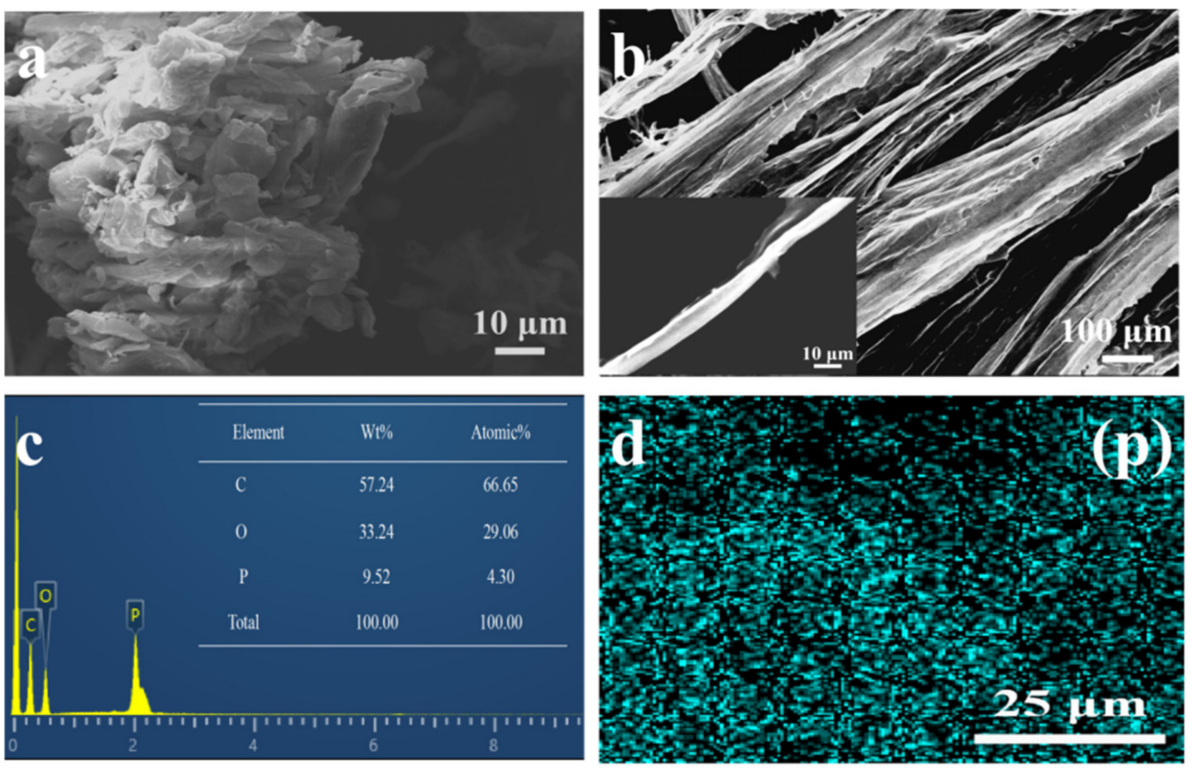

Figure 4. SEM images of cellulose (a) and PCF (b); (c) EDS spectra of the PCF; (d) the PCF with elemental mapping images of $P$.

\subsection{Curing Temperature of $B a$ and Ba/PCF Systems}

The Curing temperatures of the $\mathrm{Ba}$ and $\mathrm{Ba} / \mathrm{PCF}$ systems were analyzed by the nonisothermal DSC at a heating rate of $10{ }^{\circ} \mathrm{C} \mathrm{min}-1$, as shown in Figure 5. The curing characteristic parameters, including the initial curing temperature $\left(T_{i}\right)$, curing peak temperature $\left(T_{p}\right)$ and final curing temperature $\left(T_{f}\right)$ are listed in Table 1. A single exothermic peak for the ring-opening thermal curing of the $\mathrm{Ba}$ and $\mathrm{Ba} / \mathrm{PCF}$ systems was observed. However, the $T_{i}$ of Ba decreased with the addition of PCF. Specifically, the $T_{i}, T_{p}$, and $T_{f}$ of Ba with $5 \%$ PCF decreased by $29^{\circ} \mathrm{C}, 5{ }^{\circ} \mathrm{C}$, and $12{ }^{\circ} \mathrm{C}$ respectively, compared with those of the pure $\mathrm{Ba}$. This phenomenon may be ascribed to the catalytic effect of PCF on Ba. This was mainly attributed to the $\mathrm{P}$ of PCF. The element $\mathrm{P}$ with empty electron orbits around the nuclei could accept the electron pairs of the $\mathrm{O}$ atom on the oxazine ring to form coordinate bonds when the PCF was mixed with the $\mathrm{Ba}$. Once the $\mathrm{P}$ atom coordinated with the $\mathrm{O}$ atom, the $-\mathrm{CH}_{2}-\mathrm{O}$ bond is prone to fragility because of the electron with the drawing nature of $\mathrm{P}$ [39]. Next, cleavage occurs to form the intermediate of iminium-ion/carbenium-ion resonance structures. The electron density of this position can be lowered by the coordination of $\mathrm{P}$ with the $\mathrm{O}$ atom [40]. The resulting phenolic hydroxyl group further catalyzes the curing reaction of Ba. Hydroxyls of PCF could interact with oxygen and nitrogen atoms in Ba monomers and resulted in the formation of inter-molecular hydrogen bonds. With the temperature increasing, hydrogen bonds broke and released free hydroxyl to accelerate the ring-opening reaction of the oxazine ring [41]. The curing temperature was set as $180^{\circ} \mathrm{C} / 2 \mathrm{~h}$, followed by $200^{\circ} \mathrm{C} / 2 \mathrm{~h}$, to fully cure the Ba monomers and $\mathrm{Ba} / \mathrm{PCF}$ mixture. 


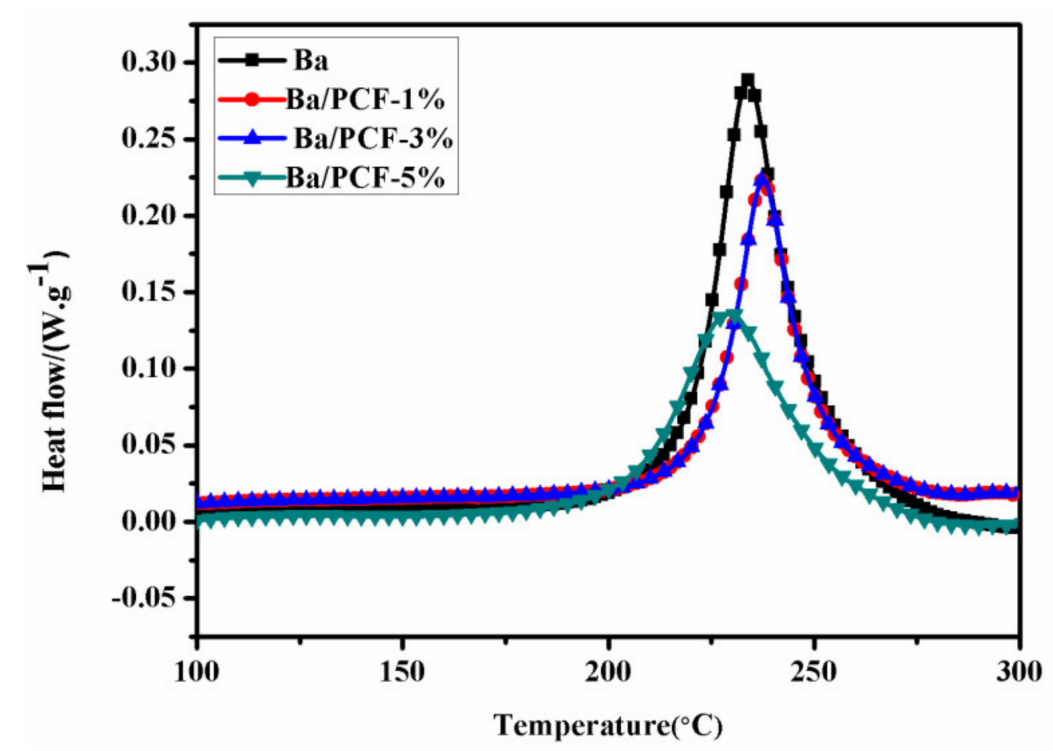

Figure 5. DSC curves of the $\mathrm{Ba}$ and $\mathrm{Ba} / \mathrm{PCF}$ systems at a heating rate of $10^{\circ} \mathrm{C} / \mathrm{min}$.

Table 1. Curing characteristic parameters of $\mathrm{Ba}$ and $\mathrm{Ba} / \mathrm{PZPT}$ systems at a heating rate of $10^{\circ} \mathrm{C} / \mathrm{min}$.

\begin{tabular}{cccc}
\hline Samples & $\mathbf{T}_{\mathbf{i}}\left({ }^{\circ} \mathbf{C}\right)$ & $\mathbf{T}_{\mathbf{p}}\left({ }^{\circ} \mathbf{C}\right)$ & $\mathbf{T}_{\mathbf{f}}\left({ }^{\circ} \mathbf{C}\right)$ \\
\hline $\mathrm{Ba}$ & 215 & 234 & 280 \\
$\mathrm{Ba} / \mathrm{PCF}-1 \%$ & 199 & 239 & 277 \\
$\mathrm{Ba} / \mathrm{PCF}-3 \%$ & 194 & 236 & 273 \\
$\mathrm{Ba} / \mathrm{PCF}-5 \%$ & 186 & 229 & 268 \\
\hline
\end{tabular}

\subsection{Thermal Stability}

The thermal stability of the PBa and its composites was detected through TGA and DTG (Figure 6$)$. The onset decomposition temperature $\left(\mathrm{T}_{\text {onset }}\right)$ expressing $5 \%$ mass loss, the temperature at the maximum mass loss rate $\left(\mathrm{T}_{\max }\right)$ and amount of char residues are collected from Figure 6a-d, which are shown in Table 2. Both the $\mathrm{T}_{\text {onset }}$ and $\mathrm{T}_{\max }$ lowered significantly with the addition of PCF, as shown in Figure 6 and Table 2 . The $\mathrm{T}_{\text {onset }}$ reduced from $331{ }^{\circ} \mathrm{C}$ for pure $\mathrm{PBa}$ to $326^{\circ} \mathrm{C}$ for $\mathrm{PBa} / \mathrm{PCF}-1 \%$ in air, and from $334{ }^{\circ} \mathrm{C}$ to $323{ }^{\circ} \mathrm{C}$ in $\mathrm{N}_{2}$. The $\mathrm{T}_{\text {onset }}$ and $\mathrm{T}_{\max }$ of the PBa/PCF- $5 \%$ composite reduced by $29^{\circ} \mathrm{C}$ and $30^{\circ} \mathrm{C}$ in an air atmosphere and by $18{ }^{\circ} \mathrm{C}$ and $39^{\circ} \mathrm{C}$ in $\mathrm{N}_{2}$, compared with than of the pure PBa. The char residue of $\mathrm{PBa}$ was $26 \%$ at $700{ }^{\circ} \mathrm{C}$, and reduced to $7 \%$ and $800{ }^{\circ} \mathrm{C}$ in air. Interestingly, the char residue's content was enhanced with the incorporation of PCF in the PBa matrix, especially at high temperatures. The char residue of $\mathrm{PBa} / \mathrm{PCF}-1 \%$ reached up to $37 \%$ at $700{ }^{\circ} \mathrm{C}$ and $34 \%$ at $800{ }^{\circ} \mathrm{C}$ in air. A slight increase in the char residue's content was observed along with the increase in the incorporation of PCF from 1\% to 5\% in the PBa, both in air and $\mathrm{N}_{2}$. The chair residue's enhancement was higher in air than in $\mathrm{N}_{2}$ above $700{ }^{\circ} \mathrm{C}$, which implied that PCF effectively promoted char formation during the combustion of $\mathrm{PBa}$, especially in air. On the whole, the thermal decomposition reaction in air exhibited almost the same tendency of $\mathrm{PBa} / \mathrm{PCF}$ composites as that in $\mathrm{N}_{2}$. 

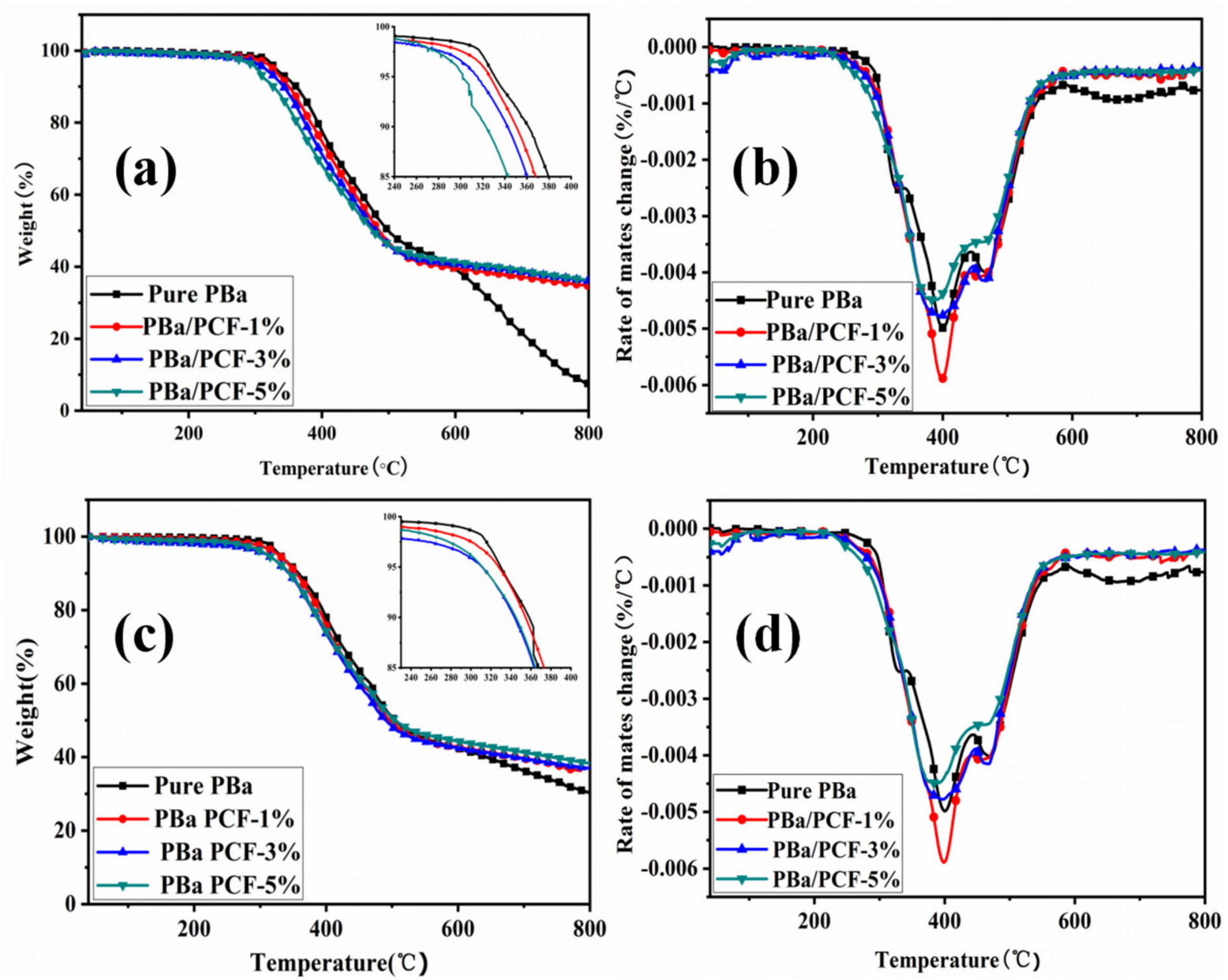

Figure 6. TGA (a) and DTG (b) curves of PBa and PBa/PCF composites in air and $\mathrm{N}_{2}$ atmospheres (c,d).

Table 2. Results of TGA of PBa and its composites in air and $\mathrm{N}_{2}$.

\begin{tabular}{|c|c|c|c|c|c|c|c|c|}
\hline \multirow{3}{*}{ Sample } & \multirow{2}{*}{\multicolumn{2}{|c|}{$\mathrm{T}_{\text {onset }}\left({ }^{\circ} \mathrm{C}\right)$}} & \multirow{2}{*}{\multicolumn{2}{|c|}{$\mathrm{T}_{\max }\left({ }^{\circ} \mathrm{C}\right)$}} & \multicolumn{4}{|c|}{ Char Residue (\%) } \\
\hline & & & & & \multicolumn{2}{|c|}{$700{ }^{\circ} \mathrm{C}$} & \multicolumn{2}{|c|}{$800{ }^{\circ} \mathrm{C}$} \\
\hline & Air & $\mathbf{N}_{2}$ & Air & $\mathbf{N}_{2}$ & Air & $\mathbf{N}_{2}$ & Air & $\mathbf{N}_{2}$ \\
\hline $\mathrm{PBa}$ & 331 & 334 & 410 & 418 & 26 & 34 & 7 & 30 \\
\hline PBa/PCF-1\% & 326 & 323 & 400 & 404 & 37 & 35 & 34 & 34 \\
\hline $\mathrm{PBa} / \mathrm{PCF}-3 \%$ & 315 & 329 & 394 & 390 & 38 & 36 & 36 & 36 \\
\hline PBa $/$ PCF-5\% & 302 & 316 & 380 & 379 & 39 & 41 & 37 & 38 \\
\hline
\end{tabular}

There were two main patterns of thermal oxidative degradation for $\mathrm{PBa}$ and its composites. The thermal decompositions all primarily appeared in the range of $300-500{ }^{\circ} \mathrm{C}$. The first step was shown in $300-420^{\circ} \mathrm{C}$. This is mostly because of the degradation of phenols and amines in the PBa matrix during combustion. Less-stable $\mathrm{O}=\mathrm{P}-\mathrm{O}$ bonds in PCF lead to lower $\mathrm{T}_{\text {initial }}$ in $\mathrm{PBa} / \mathrm{PCF}$ composites. Groups containing phosphorus decompose to react with $\mathrm{PBa}$ during heating, which can accelerate the degradation of $\mathrm{PBa}$ composite to form a stable char layer [42]. In addition, phosphoric acid, polymetaphosphoric acid, $\mathrm{H}_{2} \mathrm{O}$ gas and so on can be produced by $\mathrm{PCF}$ above $300^{\circ} \mathrm{C}$ [43], which can help stable char residue to resist the heat and substance transfer, thus preventing further decomposition. The second stage is $420-500{ }^{\circ} \mathrm{C}$, which mainly corresponds to a further thermal degradation and crosslinking reaction among phosphate groups and the main chain of PBa molecule, resulting char layers. These char layers on the surface of the matrix are able to generate an effective physical barrier to retard the transfer of gases, heat and interior thermal decomposition products. Hence, they prevent combustion. 


\subsection{Flammability Performance of $\mathrm{PBa}$ and Its Composites}

UL-94 vertical burning testing and LOI were used to measure the influence of PCF on the flame retardancy of PBa. The LOI value was 21 for pure PBa, which increased to 24,28 and 31 with the loading of PCF $1 \%, 3 \%$ and $5 \%$ in the PBa matrix, respectively. In addition, the UL-94 level improved from the NO level to the V0 level. The results of the UL-94 vertical burning and LOI testing demonstrate the contribution of PCF in PBa to the flame retardant properties.

Cone calorimeter (CONE) is a fire testing instrument that can assess the flammability characteristics and potential fire safety of polymers. CONE tests were used to evaluate the properties of the PBa composites when burning. The heat release rate (HRR), total heat release (THR), carbon monoxide production (COP) and total smoke release (TSR) are shown in Figure 7. The time-to-ignition (TTI), peak of HRR (PHRR), average heat release rate (AvHRR) and mass loss rate are presented in Table 3.
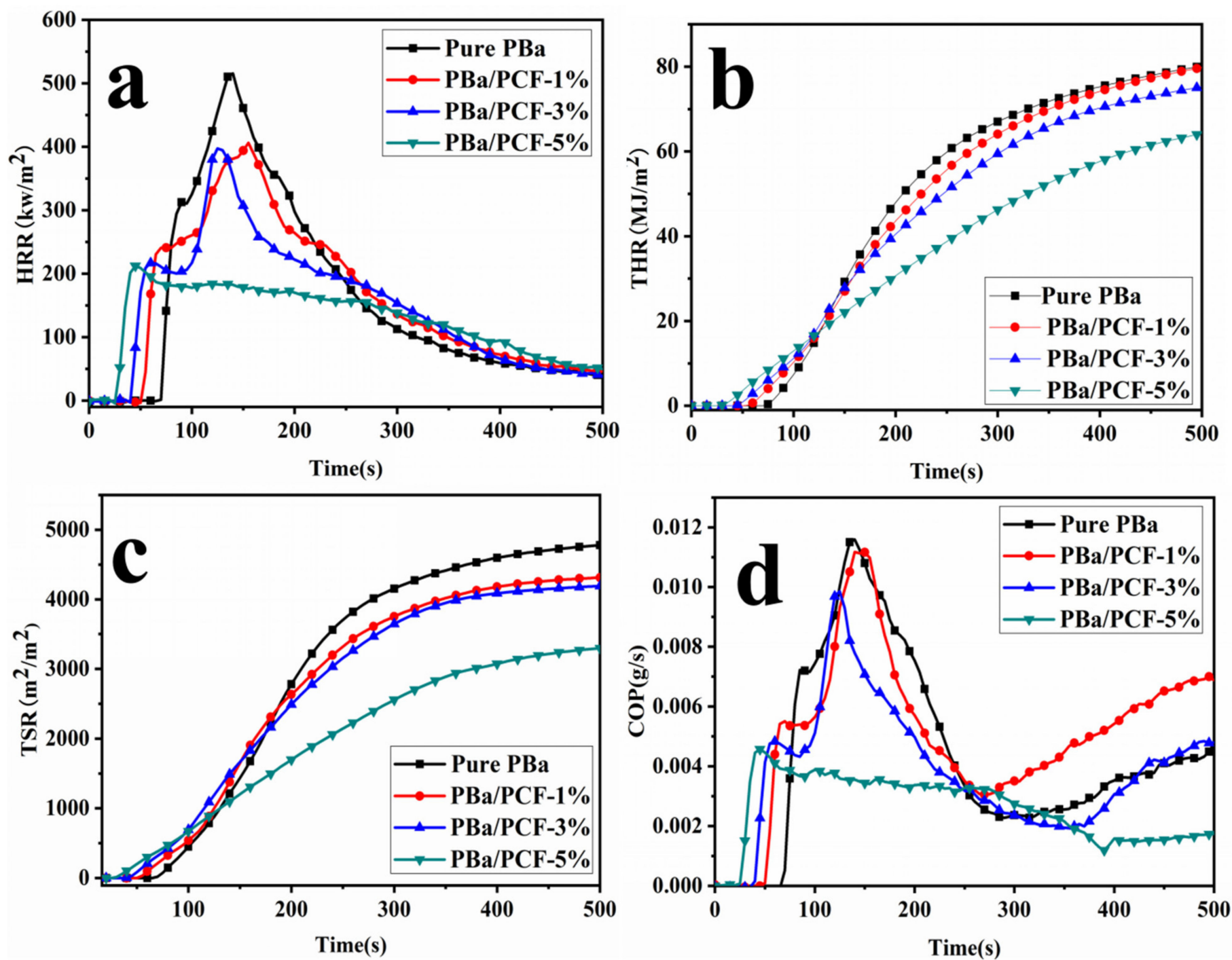

Figure 7. HRR (a), THR (b), TSR (c), and COP (d) versus time curves of PBa and PBa/PCF composites obtained from CONE test. 
Table 3. CONE parameters, LOI and UL-94 results of PBa and its composites.

\begin{tabular}{ccccccc}
\hline Sample & TTI(S) & PHRR((kW/m $\left.{ }^{2}\right)$ & AvHRR(kW/m $\left.{ }^{2}\right)$ & Mass Loss(\%) & LOI(\%) & UL-94 \\
\hline Pure PBa & 66 & 515.6 & 158.3 & $74.5 \%$ & 21 & NO \\
PBa/PCF-1\% & 50 & 406.1 & 152.8 & $75.9 \%$ & 24 & V-1 \\
PBa/PCF-3\% & 39 & 397.2 & 163.6 & $68.9 \%$ & 28 & V-1 \\
PBa/PCF-5\% & 23 & 212.3 & 110.3 & $65.9 \%$ & 31 & V0 \\
\hline
\end{tabular}

Time-to-ignition (TTI) is used to test the effect of PCF on ignitability. It can be observed in Table 3 that the TTI value of the original PBa was longer than that of the PBa composites. Specially, the TTI value of $\mathrm{PBa} / \mathrm{PCF}-5 \%$ was only $23 \mathrm{~s}$, which was much shorter than the value of $66 \mathrm{~s}$ obtained for the pure PBa. This may have been because the instability of $\mathrm{P}-\mathrm{O}$ and $\mathrm{P}=\mathrm{O}$ of the PCF could shorten the TTI [44-46], which promotes the formation of the cross-linking structure in PBa composites, decreases the decomposition of $\mathrm{PBa}$ and improves the flame retardancy of the matrix. The AvHRR of composites decreases significantly with the incorporation of PCF (Table 3). The PBa/PCF-5\% displayed an AvHRR of $110.3 \mathrm{~kW} / \mathrm{m}^{2}$, which was $30.3 \%$ lower than that of the pure PBa. Meanwhile, the mass loss rate of the PBa/PCF- $5 \%$ reduced from $74.5 \%$ to $65.9 \%$, compared with original PBa. The combination of the lower value of AvHRR and the mass loss rate demonstrate that PBa composites could partially undergo a process of char formation rather than burning.

In Figure 7a and Table 3, it can be observed that the PHRR values for the PBa/PCF-5\% notably decreased. The PHRR was $212.3 \mathrm{~kW} / \mathrm{m}^{2}$ for the PBa/PCF-5\%, with a reduction of $58.8 \%$ compared with the PBa. These phenomena indicated the superior fire performance of composites. The distinct reduction in PHRR was mainly due to the cross-linking char formation process promoted by the introduction of PCF in the PBa. Figure $7 \mathrm{~b}$ exhibits the THR curves for the PBa/PCF composites. A significant finding is that the value of THR for pure PBa decreased from 83.9 to $70.1 \mathrm{MJ} / \mathrm{m}^{2}$ compared with the PBa/PCF-5\%. The crosslinked char layer formed during the carbonization process of the $\mathrm{PBa} / \mathrm{PCF}$ composites can produce a physical barrier, which contributes to a reduction in matter transformation during the burning process and in the risk of fire. As is well known, smoke causes more deaths than burning. Meanwhile, the production of soot mainly resulted in incomplete combustion during the burning of the polymers. The decrease in TSR (Figure 7c) implies that the loading of PCF has a significant smoke-suppressing effect in PBa composites, resulting in a decreased risk of asphyxiation in a fire disaster. The value of COP can be used to assess the toxicity of materials in combustion. The loading of PCF, especially with $5 \%$ content, clearly reduced the COP value in comparison with the original PBa (Figure 7d). The loading of PCF can significantly decrease the amount of $\mathrm{CO}$ and reduce toxicity during the combustion process of $\mathrm{PBa} / \mathrm{PCF}$ composites. Consequently the prepared PBa/PCF composites can save time for safe evacuation during a fire.

\subsection{Analysis of Flame Retardancy Mechanism \\ 3.6.1. Condensed Phase Analysis}

The analysis of residual chars could provide an insight into flame resistant properties and further reveal the possible mechanisms of char formation for flame retardant materials [47]. High-quality char can act as a good insulating barrier to greatly limit the diffusion of volatiles into the flame zone. The morphology of the residual char of the pure $\mathrm{PBa}$ and $\mathrm{PBa}$ composites obtained from the CONE tests was observed through SEM, as shown in Figure 8. The char layers of the pure PBa and the PBa/PCF-1\% were broken and cracked, as demonstrated in Figure 8a,b. However, the PBa/PCF-3\% and PBa/PCF-5\% exhibited continuous, compact and tight char surfaces, as demonstrated in Figure 8c,d. These phenomena fully prove that a higher incorporation of PCF can improve the quality of the char layer more effectively during burning. SEM images of the outside surface and inner structure of the pristine PBa and PBa/PCF char layers are presented in Figure 8(a1-d2). The residual chars of the pure $\mathrm{PBa}$ were poor in flexibility and prone to destruction; therefore, they cannot inhibit $\mathrm{CO}$ and $\mathrm{CO}_{2}$ gases or protect the PBa matrix. Nevertheless, as shown 
in Figure 8(b1-d1), with the loading of PCF, the inner structures of the composites' charred layers became more consecutive, uniform, bumpy and porous, with many smaller hollow cells. Meanwhile, the PBa/PCF-5\% exhibited the most continuous and compact outer surface, as shown in Figure 8(a2,d2). This suggests that PCF is the key factor in the formation of high-quality intumescent char layers. Generally speaking, intumescent charred layers help to slow down the exchange of heat and mass between the gas and solid phases, which can offer a better flame shield for underlying polymers during degradation.
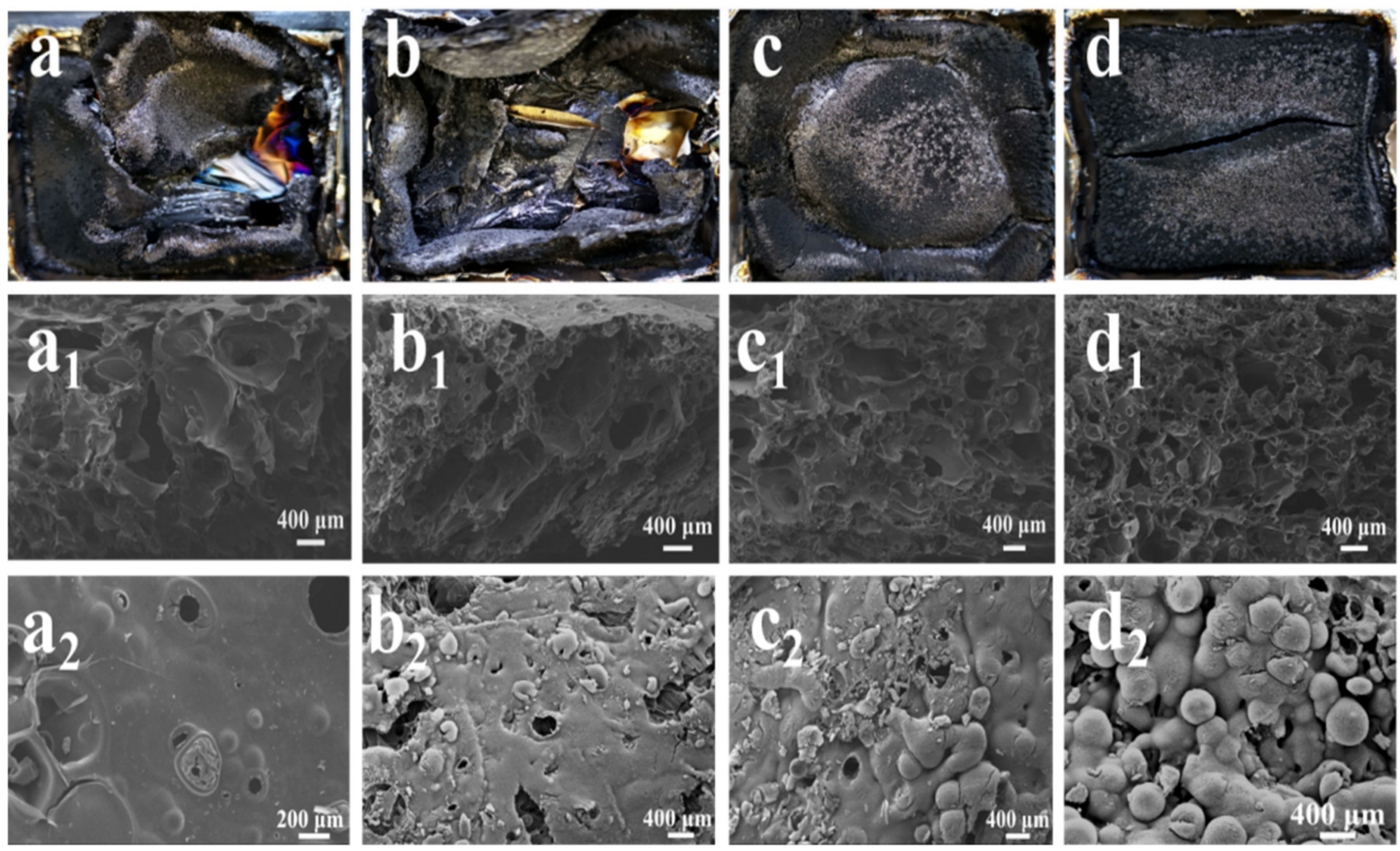

Figure 8. Digital photographs of the char layers (a-d) and SEM images of the residual char interior regions $\left(\mathbf{a}_{\mathbf{1}}-\mathbf{d}_{\mathbf{1}}\right)$ and outside surfaces $\left(\mathbf{a}_{2}-\mathbf{d}_{2}\right.$ ) of (a) pure PBa, (b) PBa/PCF-1\%, (c) PBa/PCF-3\% and (d) PBa/PCF-5\%.

As is well known, phosphorus-based flame retardants can accelerate the degradation reaction of polymer materials [44-46]. The PCF in PBa matrix underwent thermal degradation during the initial decomposing stage to form polyphosphoric acid, which can be cross-link-reacted with PBa during burning. The dehydration reaction depends on the hydroxyl groups in $\mathrm{PBa}$, which can form a cross-linked network structure during the preliminary decomposition. Next, the firm and intumescent charred layer is formed to protect the polymer's interior significantly. Furthermore, intumescent flame retardants exert a synergistic flame-retardant effect between the acid, gas, and charring source. In this study, the acid source was PCF, and PBa was the gas and charring source [43]. In the process of combustion, the acid source effectively improved the carbonization of the PBa, which formed a compact and continuous charring layer and hindered the thermal decomposition of the $\mathrm{PBa}$, resulting in the prohibition of the mass and heat transfer. The oxygen concentration was diluted by the generated noncombustible gas, which improved the flame-retardant's performance. When the amount of oxygen and heat in the environment is insufficient, it is difficult for the material to burn, which leads to self-extinguishment [48].

Raman spectroscopy was employed to investigate the structure of the char residues obtained from the CONE test. The char residues exhibited two characteristic bands, as presented in Figure 9. The D band at $1315 \mathrm{~cm}^{-1}$ and the $\mathrm{G}$ band at $1550 \mathrm{~cm}^{-1}$ contributed the vibration of amorphous carbon and the vibration of crystalline graphite carbon, respectively. In general, the integral area ratio $\left(\mathrm{I}_{\mathrm{D}} / \mathrm{I}_{\mathrm{G}}\right)$ of the two bands was dependent on the graphitization degree of the carbonaceous materials. The lower $\mathrm{I}_{\mathrm{D}} / \mathrm{I}_{\mathrm{G}}$ value demonstrated a higher graphitization degree. It can be inferred that the $\mathrm{I}_{\mathrm{D}} / \mathrm{I}_{\mathrm{G}}$ values of the pure $\mathrm{PBa}$ and $\mathrm{PBa} / \mathrm{PCF}$ nanocomposites were 1.023, 1.023, 1.018 and 1.016, respectively. Clearly, with the 
addition of $P C F$, the $I_{D} / I_{G}$ values reduced. This phenomenon implies that the char layers of $\mathrm{PBa} / \mathrm{PCF}$ composites were more compact compared with the original PBa. The results and the discussion of the Raman spectroscopy were in good agreement with those of the SEM.

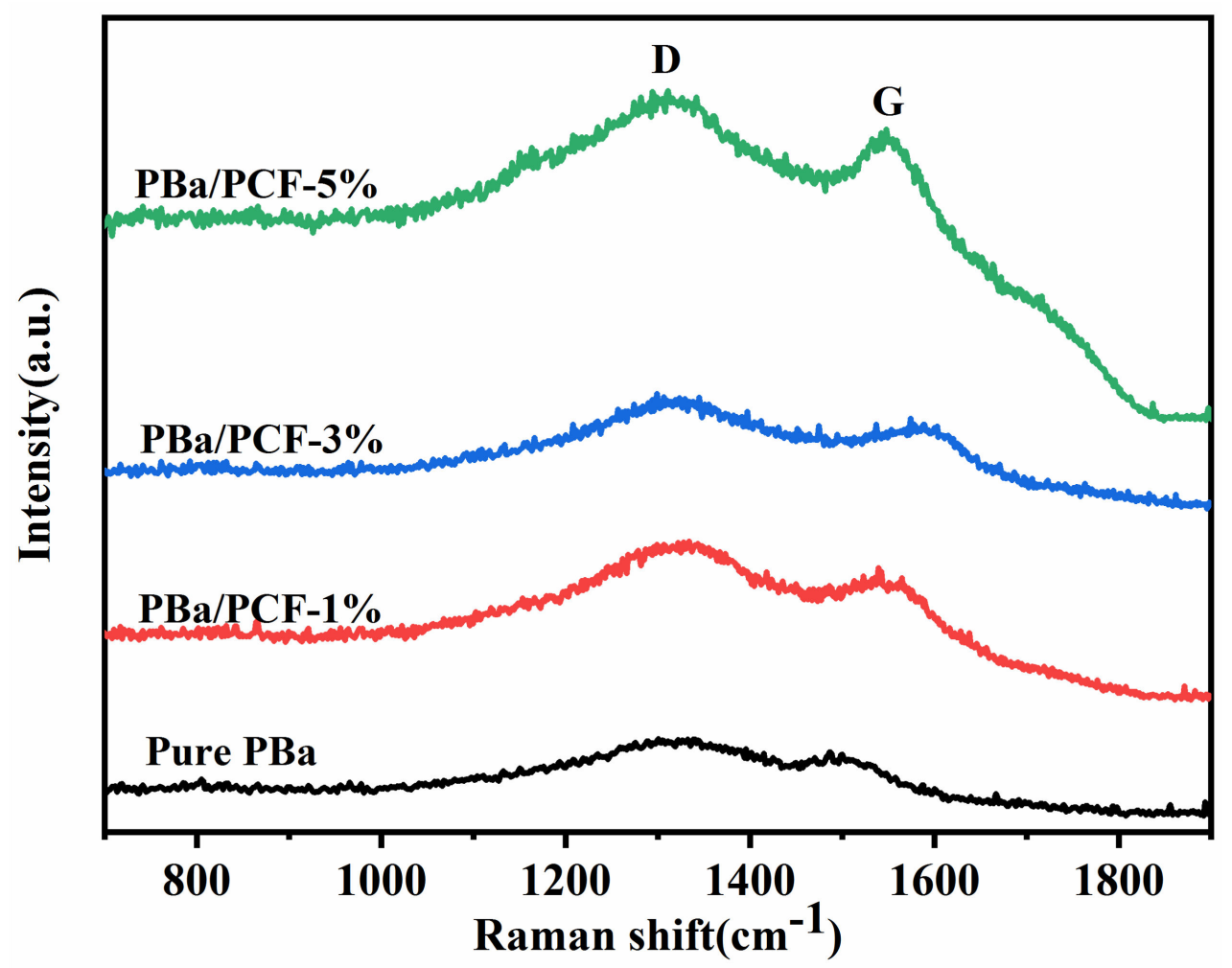

Figure 9. Raman spectra of char residues for samples collected from CONE test.

\subsubsection{Gas Phase Analysis}

In order to directly distinguish the changes in the peak intensities of the main pyrolysis products of $\mathrm{PBa}$ and its composites at various temperatures, TG-FTIR tests were carried out. The results are described in Figures 10 and 11. The main pyrolysis products of pure $\mathrm{PBa}$ during thermal decomposition were water and amine-containing compounds (3500-3800 $\left.\mathrm{cm}^{-1}\right)$, compounds containing alkane $\left(2900-3000 \mathrm{~cm}^{-1}\right), \mathrm{CO}_{2}\left(2350 \mathrm{~cm}^{-1}\right)$, and aromatic compounds (1500-1750 $\mathrm{cm}^{-1}$ ). The loading of PCF contributed an early release of water, amine-containing compounds, hydrocarbons, $\mathrm{CO}_{2}$ and the aromatic compounds compared with pure PBa. This phenomenon revealed that the addition of PCF played a significant part in catalyzing the thermal decomposition of the PBa. To compare precisely, the FTIR spectra of the gas phase for pure the $\mathrm{PBa}$ and $\mathrm{PBa} / \mathrm{PCF}-5 \%$ at various temperatures are presented in Figure 11. The characteristic bands for the common gaseous products of $\mathrm{PBa} / \mathrm{PCF}-5 \%$ were mostly same as those of the pristine PBa. PBa/PCF-5\% exhibited a new, strengthened peak at around $1269 \mathrm{~cm}^{-1}$, which was due to the characteristic adsorption of the $-\mathrm{P}-\mathrm{O}-$ bond. This implied that some of the phosphorous groups in the $\mathrm{PBa} / \mathrm{PCF}$ composites degraded thermally into the gaseous phase. Free radicals could effectively capture or terminate in the gas phase, so that the process of heating or combustion was delayed. Finally, PCF plays the role of flame retardant in PBa/PCF composites. 

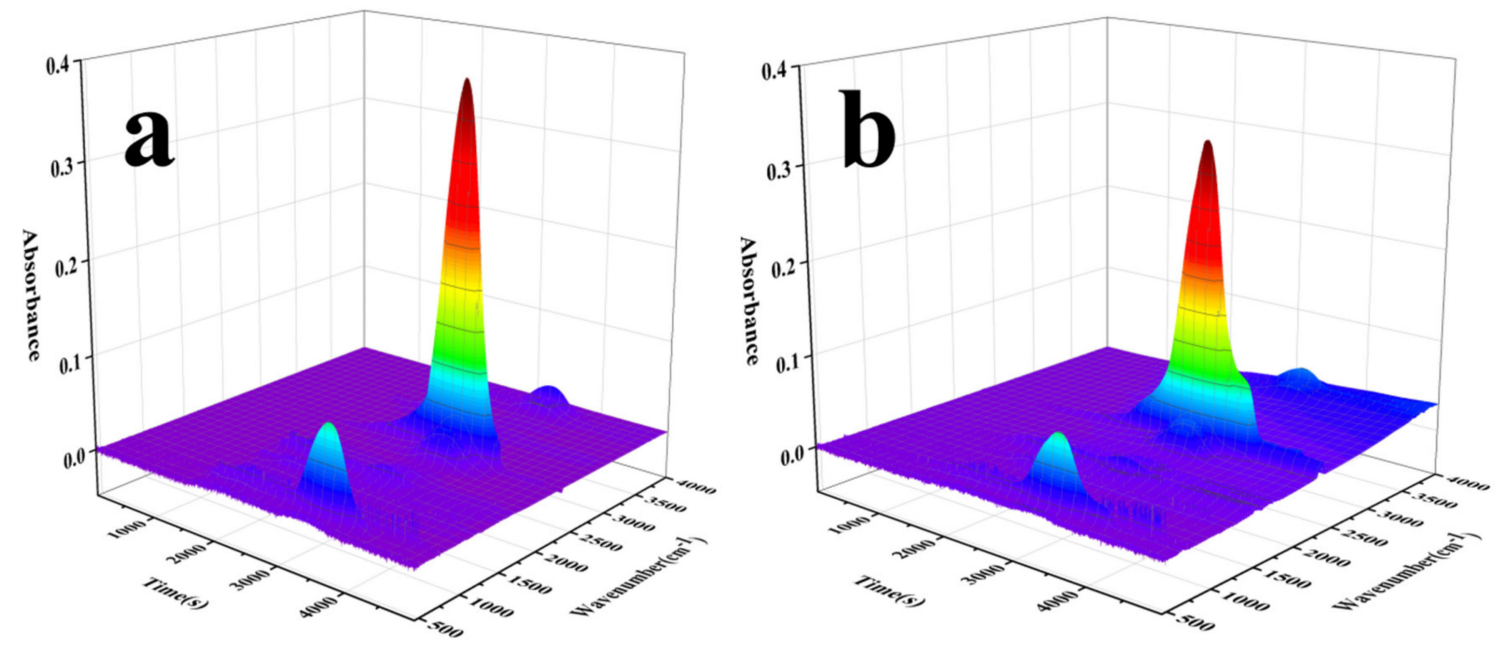

Figure 10. 3D TG-FTIR images of pyrolysis products of (a) Pure PBa and (b) PBa/PCF-5\%.
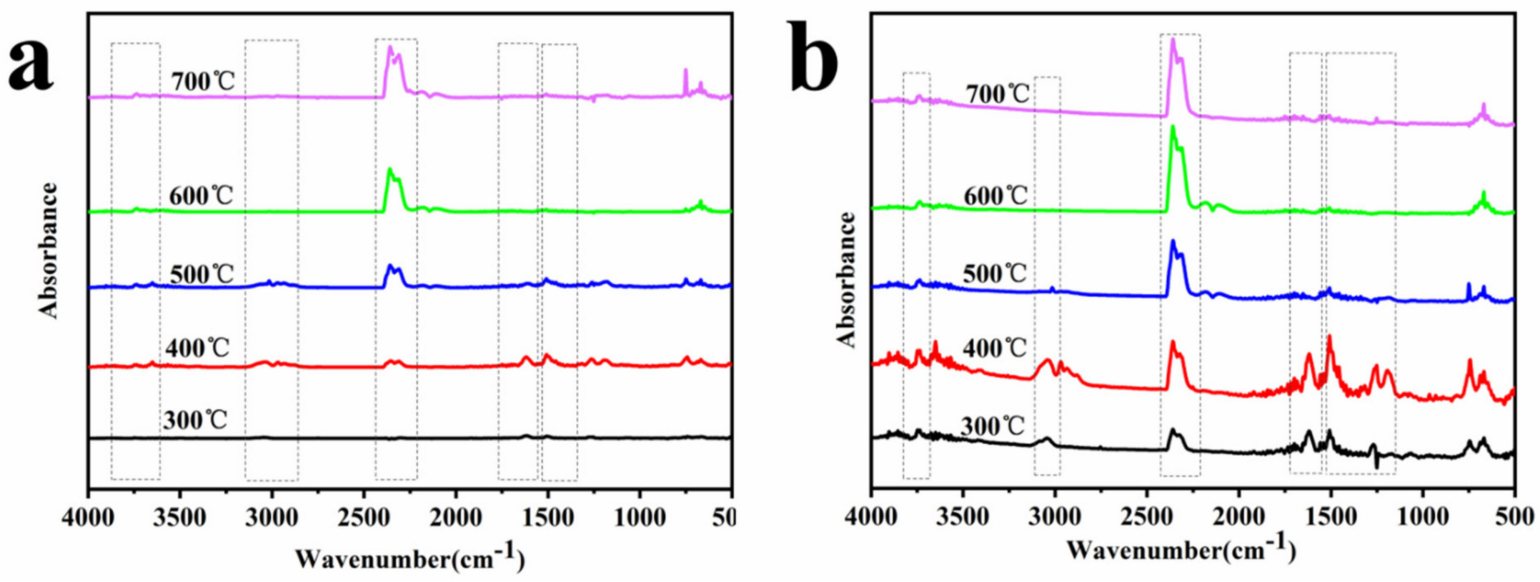

Figure 11. FTIR spectra of (a) pure PBa and (b) PBa/PCF-5\% at different temperatures.

\subsection{Dynamic Mechanical Properties}

The significance of PCF in enhancing the flame retardancy of PBa was demonstrated through the results presented above. A halogen-free method to enhance the flame retardancy of polymers without sacrificing glass transition temperature $\left(\mathrm{T}_{\mathrm{g}}\right)$ and storage modulus is important for the purposes of academic research and industrial applications. The dynamic mechanical properties of pure $\mathrm{PBa}$ and its composites were measured by DMA, and the results are presented in Figures 12 and 13.

The storage modulus of the $\mathrm{PBa} / \mathrm{PCF}$ composites slightly decreased below $\mathrm{T}_{\mathrm{g}}$ compared with that of the pure PBa (Figure 12), which was mainly due to the lower crosslink density caused by the inert additives of PCF. A similar phenomenon was observed for the $\mathrm{T}_{\mathrm{g}}$ of the PBa/PCF- $1 \%$ and PBa/PCF- $5 \%$. The neat PBa exhibited a $\mathrm{T}_{\mathrm{g}}$ at $235^{\circ} \mathrm{C}$. The $\mathrm{T}_{\mathrm{g}}$ of the PBa decreased to $231{ }^{\circ} \mathrm{C}$ with the incorporation of $1 \% \mathrm{PCF}$ and to $222^{\circ} \mathrm{C}$ with $5 \% \mathrm{PCF}$, which was also mainly caused by the under-curing of the PBa (Figure 13). Meanwhile, PCF is a rigid additive with abundant $-\mathrm{OH}$ groups, which can form hydrogen bonds with $-\mathrm{OH}$ in the PBa chain. The rigid backbones of PCF and the hydrogen bonding in the composite matrix can restrict the chain segment motion. The combination of the under-curing, the rigid structure of PCF and the hydrogen bonding resulted in the highest $\mathrm{T}_{\mathrm{g}}$ at $241^{\circ} \mathrm{C}$ and a storage modulus at $220-250{ }^{\circ} \mathrm{C}$ for the $\mathrm{PBa} / \mathrm{PCF}-3 \%$. In any event, the values of $\mathrm{T}_{\mathrm{g}}$ were all still above $200^{\circ} \mathrm{C}$ and were higher than those of traditional thermosetting resins. PCF 
produces no significant effects on the application temperature and working environment of PBa.

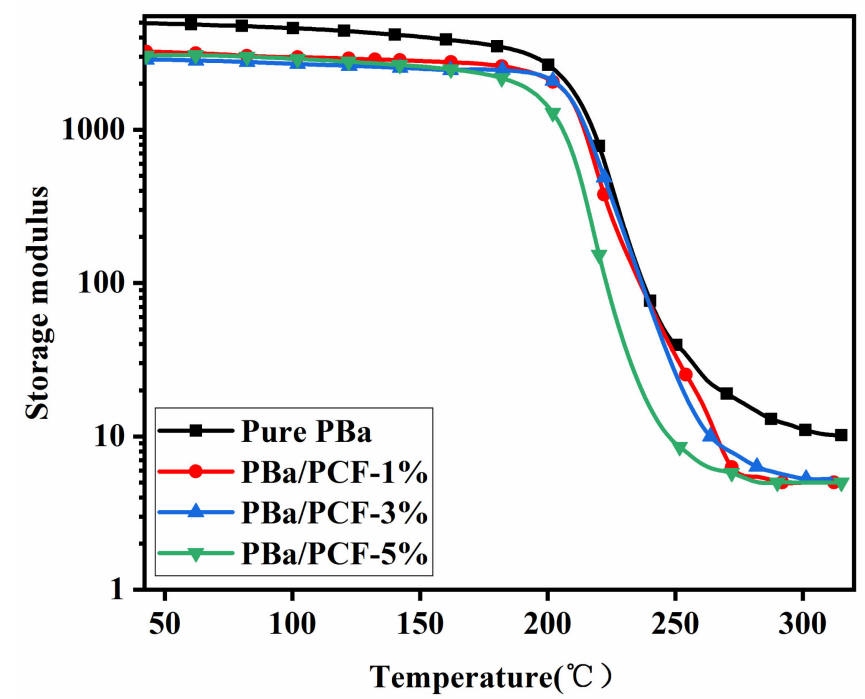

Figure 12. Storage modulus of $\mathrm{PBa}, \mathrm{PBa} / \mathrm{PCF}-1 \%$ and $\mathrm{PBa} / \mathrm{PCF}-3 \%$ and $\mathrm{PBa} / \mathrm{PCF}-5 \%$.

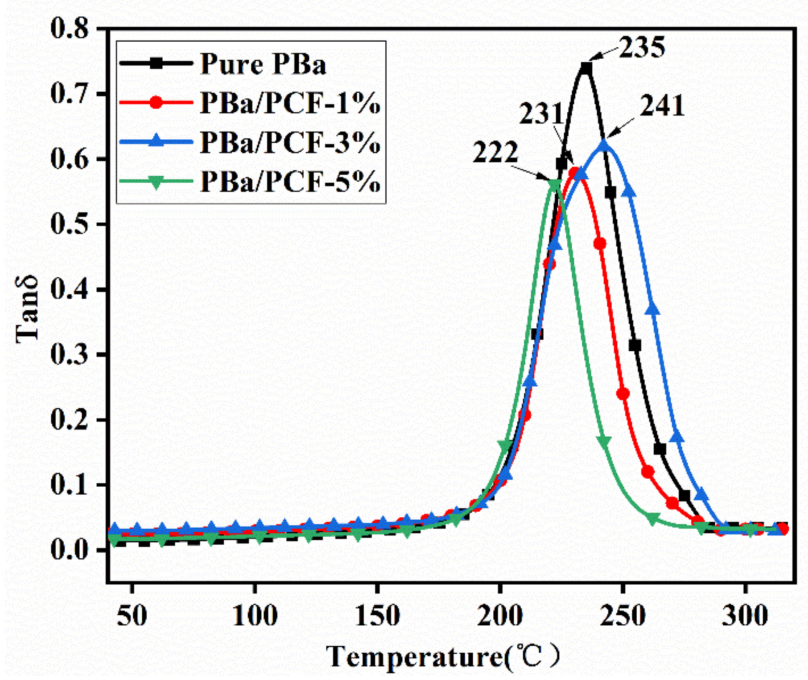

Figure 13. Tan $\delta$ of PBa, PBa/PCF-1\%, PBa/PCF-3\% and PBa/PCF-5\%.

\section{Conclusions}

$\mathrm{PBa} / \mathrm{PCF}$ composites were successfully fabricated and measured carefully. The effects of PCF on the thermal and flame retardancy properties of PBa were analyzed using several methods, such as DSC, TGA, CONE, and DMA. The curing temperature of $\mathrm{PBa} / \mathrm{PCF}-5 \%$ reduced by $5{ }^{\circ} \mathrm{C}$ compared with pure PBa. The CONE and TGA analyses fully proved that the improvement in the flame retardant property of PBa was mainly due to the high weight ratio of the charred residual. The honeycomb structure of the char residue with the compact surface acted as an effective barrier for the exchange of oxygen, flame and material matrix. Furthermore, the AvHRR and mass loss values of PBa/PCF- $5 \%$ decreased by $30.3 \%$ and $8.6 \%$, respectively, compared with $\mathrm{PBa}$. The $\mathrm{T}_{\mathrm{g}}$ of the $\mathrm{PBa}$ composites was high, above $200{ }^{\circ} \mathrm{C}$, which does not limit the application of these flame retardancy materials. This study showed that the preparation of PCF could improve many potential applications of PBa in engineering materials. 
Author Contributions: Conceptualization, H.L.; writing-original draft, Z.S.; writing-review and editing, C.Z.; data curation, Y.L. and C.Z.; formal analysis, D.X. and H.L.; methodology, Y.W. and Z.S.; software, J.W.; visualization, Y.Q. All authors have read and agreed to the published version of the manuscript.

Funding: This work was funded by Young Scholars Development Fund of SWPU (grant number 201331010075), Sichuan Science and Technology Program (grant number 2021YFH0031), National Key Research and Development Program of China (grant number 2019YFE0120300).

Institutional Review Board Statement: Not applicable.

Informed Consent Statement: Not applicable.

Data Availability Statement: Not applicable.

Conflicts of Interest: The authors declare no conflict of interest.

\section{References}

1. Ghosh, N.; Kiskan, B.; Yagci, Y. Polybenzoxazines-New high performance thermosetting resins: Synthesis and properties. Prog. Polym. Sci. 2007, 32, 1344-1391. [CrossRef]

2. Nair, C.P.R. Advances in addition-cure phenolic resins. Prog. Polym. Sci. 2004, 29, 401-498. [CrossRef]

3. Takeichi, T.; Agag, T. High performance polybenzoxazines as novel thermosets. High Perform. Polym. 2006, 18, 777-797. [CrossRef]

4. Jubsilp, C.; Taewattana, R.; Takeichi, T.; Rimdusit, S. Investigation on rubber-modified polybenzoxazine composites for lubricating material applications. J. Mater. Eng. Perform. 2015, 24, 3958-3968. [CrossRef]

5. Wang, D.Y.; Liu, Y.; Wang, Y.Z.; Artiles, C.P.; Hull, T.R.; Price, D. Fire retardancy of a reactively extruded intumescent flame retardant polyethylene system enhanced by metal chelates. Polym. Degrad. Stab. 2017, 92, 1592-1598. [CrossRef]

6. Liu, Y.; Ran, Q.; Gu, Y. Preparation and properties of benzoxazine blends with intumescent flame retardancy. Polym. Degrad. Stab. 2019, 163, 15-24. [CrossRef]

7. Xu, Y.; Dai, J.; Ran, Q.; Gu, Y. Greatly improved thermal properties of polybenzoxazine via modification by acetylene/aldehyde groups. Polymer 2017, 123, 232-239. [CrossRef]

8. Jubsilp, C.; Singto, J.; Yamo, W.; Rimdusit, S. Effect of graphite particles size on tribological and mechanical properties of polybenzoxazine composites. Chem. Eng. Transac. 2017, 57, 1351-1356.

9. Wan, L.; Wang, J.; Xie, L.; Sun, Y.; Li, K. Nitrogen-enriched hierarchically porous carbons prepared from polybenzoxazine for high-performance supercapacitors. ACS Appl. Mater. Interfaces 2014, 6, 15583-15596. [CrossRef] [PubMed]

10. Sha, X.L.; Yuan, L.; Liang, G.Z.; Gu, A.J. Development and mechanism of high-performance fully biobased shape memory benzoxazine resins with a green strategy. ACS Sustain. Chem. Eng. 2020, 8, 18696-18705. [CrossRef]

11. Zhang, K.; Han, M.; Liu, Y.; Froimowicz, P. Design and synthesis of bio-based high-performance trioxazine benzoxazine resin via natural renewable resources. ACS Sustain. Chem. Eng. 2019, 7, 9399-9407. [CrossRef]

12. Zhang, L.; Yang, Y.; Chen, Y.; Lu, H. Cardanol-capped main-chain benzoxazine oli-gomers for resin transfer molding. Eur. Polym. J. 2017, 93, 284-293. [CrossRef]

13. Su, Y.C.; Chang, F.C. Synthesis and characterization of fluorinated polybenzoxazine material with low dielectric constant. Polymer 2013, 44, 7989-7996. [CrossRef]

14. Zhu, Y.F.; Jiang, Y.H.; Lin, R.S.; Yu, S.J. Research on thermal degradation process of p-nitrophenol-based polybenzoxazine. Polym. Degrad. Stab. 2017, 141, 1-10. [CrossRef]

15. Lin, C.H.; Huang, S.J.; Wang, P.J.; Lin, H.T.; Dai, S.A. Mis-cibility, microstructure, and thermal and dielectric properties of reactive blends of dicyanate ester and diamine-based benzoxazine. Macromolecules 2012, 45, 7461-7466. [CrossRef]

16. Chen, M.J.; Shao, Z.B.; Wang, X.L.; Chen, L.; Wang, Y.Z. Halogen-free flame-retardant flexible polyurethane foam with a novel nitrogen-phosphorus flame retardant. Ind. Eng. Chem. Res. 2012, 51, 9769-9776. [CrossRef]

17. Marset, D.; Dolza, C.; Fages, E.; Gonga, E.; Gutiérrez, O.; Gomez-Caturla, J.; Ivorra-Martinez, J.; Sanchez-Nacher, L.; QuilesCarrillo, L. The Effect of Halloysite Nanotubes on the Fire Retardancy Properties of Partially Biobased Polyamide 610. Polymers 2020, 12, 3050. [CrossRef]

18. Demir, K.D.; Tasdelen, M.A.; Uyar, T.; Kawaguchi, A.W.; Sudo, A.; Endo, T.; Yagci, Y. Synthesis of polybenzoxazine/clay nanocomposites by in situ thermal ring-opening polymerization using intercalated monomer. J. Polym. Sci. Part A Polym Chem. 2011, 49, 4213-4220. [CrossRef]

19. Zhao, C.X.; Li, P.; He, D.; Li, Y.T.; Lei, F.; Sue, H.J. Flame retardation behavior of polybenzoxazine/a-ZrP nanocomposites. RSC Adv. 2016, 6, 73485-73495. [CrossRef]

20. Zhao, L.; Zhao, C.X.; Guo, C.Y.; Li, Y.T.; Li, S.L.; Sun, L.Y.; Li, H.; Xiang, D. Polybenzoxazine resins with polyphosphazene microspheres: Synthesis, flame retardancy, mechanisms, and applications. ACS Omega 2019, 4, 20275-20284. [CrossRef]

21. Shao, Z.B.; Zhang, M.X.; Li, Y.; Han, Y.; Ren, L.; Deng, C. A novel multi-functional polymeric curing agent: Synthesis, characterization, and its epoxy resin with simultaneous excellent flame retardance and transparency. Chem. Eng. J. 2018, 345, 471-482. [CrossRef] 
22. Chen, H.; Deng, C.; Zhao, Z.Y.; Wan, L.; Wang, Y.Z. Novel piperazine-containing oligomer as flame retardant and crystallization induction additive for thermoplastics polyurethane. Chem. Eng. J. 2020, 400, 125941-125954. [CrossRef]

23. Zhang, S.; Liu, X.; Jin, X.; Li, H.; Sun, J.; Gu, X. The novel application of chitosan: Effects of cross-linked chitosan on the fire performance of thermoplastic polyurethane. Carbohydr. Polym. 2018, 189, 313-321. [CrossRef] [PubMed]

24. Liu, X.; Gu, X.; Sun, J.; Zhang, S. Preparation and characterization of chitosan derivatives and their application as flame retardants in thermoplastic polyurethane. Carbohydr. Polym. 2017, 167, 356-364. [CrossRef] [PubMed]

25. Jian, R.K.; Ai, Y.F.; Xia, L.; Zhang, Z.P.; Wang, D.Y. Organophosphorus heteroaromatic compound towards mechanically reinforced and low-flammability epoxy resin. Composites 2019, 168, 458-466. [CrossRef]

26. Jiang, Z.; Li, H.; He, Y.; Liu, Y.; Dong, C.; Zhu, P. Flame retardancy and thermal behavior of cotton fabrics based on a novel phosphorus-containing siloxane. Appl. Surf. Sci. 2019, 479, 765-775. [CrossRef]

27. Cao, Z.J.; Wang, L.; Wang, S.X.; Zhao, H.B.; Wang, Y.Z. Polyurethane foams with functionalized graphene towards high fire-resistance, low smoke release, superior thermal insulation. Chem. Eng. J. 2019, 361, 1245-1254. [CrossRef]

28. Zhan, Y.; Wu, X.; Wang, S.S.; Yuan, B.H.; Fang, Q.; Shang, S.; Chao, C.; Chen, G.Q. Synthesis of a bio-based flame retardant via a facile strategy and its synergistic effect with ammonium polyphosphate on the flame retardancy of polylactic acid. Polym. Degrad. Stab. 2021, 191, 109684-109697. [CrossRef]

29. Réti, C.; Casetta, M.; Duquesne, S.; Bourbigot, S.; Delobel, R. Flammability properties of intumescent PLA including starch and lignin. Polym. Adv. Technol. 2010, 19, 628-635. [CrossRef]

30. Feng, J.X.; Su, S.P.; Zhu, J. An intumescent flame retardant system using $\beta$-cyclodextrin as a carbon source in polylactic acid (PLA). Polym. Adv. Technol. 2011, 22, 1115-1122. [CrossRef]

31. Jing, J.; Zhang, Y.; Tang, X.; Fang, Z.P. Synthesis of a highly efficient phosphorus-containing flame retardant utilizing plant-derived diphenolic acids and its application in polylactic acid. RSC Adv. 2016, 6, 49019-49027. [CrossRef]

32. Thirukumaran, P.; Parveen, A.S.; Shanmugam, M.; Kim, S.C. Development of sustainable and antimicrobial film based on polybenzoxazine and cellulose. Int. J. Biol. Macromol. 2020, 170, 664-673.

33. Dana, M.S.; Gabrielle, C.C.; Valentin, I.P. Phosphorylation of polysaccharides: New results on synthesis and characterisation of phosphorylated cellulose. React. Funct. Polym. 2006, 66, 1240-1249.

34. Maryam, G.; Federico, C.; Tomas, L.P.; Lars, W. Phosphorylated cellulose nanofibrils: A renewable nanomaterial for the preparation of intrinsically flame-retardant materials. Biomacromolecules 2015, 16, 3399-3410.

35. Moon, R.J.; Martini, A.; Nairn, J.; Simonsen, J.; Youngblood, J. Cellulose nanomaterials review: Structure, properties and nanocomposites. Chem. Soc. Rev. 2011, 40, 3941-3994. [CrossRef] [PubMed]

36. Sander, M.; Steininger, E. Chapter 5: Phosphorylation of Polymers. J. Macromol. Sci. C 1968, 2, 57-72. [CrossRef]

37. Chen, H.B.; Wang, W.Z.; Sanchez-Soto, M.; Schiraldi, D.A. Low flammability, foam-like materials based on ammonium alginate and sodium montmorillonite clay. Polymer 2012, 53, 825-831. [CrossRef]

38. Kotzebue, L.R.V.; Ribeiro, F.W.M.; Sombra, V.G.; Feitosa, J.P.A.; Mele, G.; Mazzetto, S.E.; Lomonaco, D. Spectral and thermal studies on the synthesis and catalyzed oligomerization of novel cardanol-based benzoxazines. Polymer 2016, 92, 189-200. [CrossRef]

39. Chutayothin, P.; Ishida, H. Cationic ring-opening polymerization of 1,3-benzoxazines: Mechanistic study using model compounds. Macromolecules 2010, 43, 4562-4572. [CrossRef]

40. Ran, Q.C.; Zhang, D.X.; Zhu, R.Q.; Gu, Y. The structural transformation during polymerization of benzoxazine/ $\mathrm{FeCl}_{3}$ and the effect on the thermal stability. Polymer 2012, 53, 4119-4127. [CrossRef]

41. Lin, R.S.; Zhu, Y.F.; Wang, L.M.; Yu, S.J. Pyrogallol-based benzoxazines with latent catalytic characteristics: The temperaturedependent effect of hydrogen bonds on ring-opening polymerization. Chem. Eng. J. 2018, 102, 141-150. [CrossRef]

42. Hu, Z.; Chen, L.; Zhao, B.; Luo, Y.; Wang, D.Y.; Wang, Y.Z. A novel efficient halogen-free flame retardant system for polycarbonate. Polym. Degrad. Stab. 2011, 96, 320-327. [CrossRef]

43. Wei, J.X.; Zhao, C.X.; Li, Y.C.; Li, Y.T.; Sun, Z.M.; Xiang, D.; Li, H. A simple and green strategy for preparing poly(vinyl alcohol)/phosphate cellulose aerogel with enhanced flame-retardant properties. Polym. Eng. Sci. 2021, 61, 693-705.

44. Yu, L.; Chen, L.; Dong, L.P.; Li, L.J.; Wang, Y.Z. Organic-inorganic hybrid flame retardant: Preparation, characterization and application in EVA. RSC Adv. 2014, 4, 17812-17821. [CrossRef]

45. Wang, X.; Romero, M.Q.; Zhang, X.Q.; Wang, R.; Wang, D.Y. Intumescent multilayer hybrid coating for flame retardant cotton fabrics based on layer-by-layer assembly and sol-gel process. RSC Adv. 2015, 5, 10647-10655. [CrossRef]

46. Sun, D.C.; Yao, Y.W. Synthesis of three novel phosphorus-containing flame retardants and their application in epoxy resins. Polym. Degrad. Stab. 2011, 96, 1720-1724. [CrossRef]

47. Qian, X.D.; Song, L.; Yuan, B.H.; Yu, B.; Shi, Y.Q.; Hu, Y.; Yuen, R.K.K. Organic/inorganic flame retardants containing phosphorus, nitrogen and silicon: Preparation and their performance on the flame retardancy of epoxy resins as a novel intumescent flame retardant system. Mater. Chem. Phys. 2014, 143, 1243-1252. [CrossRef]

48. Qian, X.D.; Song, L.; Hu, Y.; Yuen, R.K.K.; Chen, Y.L.; Guo, Y.Q.; Hong, N.N.; Jiang, S.H. Combustion and thermal degradation mechanism of a novel intumescent flame retardant for epoxy acrylate containing phosphorus and nitrogen. Ind. Eng. Chem. Res. 2011, 50, 266-270. [CrossRef] 